Livia dan Nuringsih: Pengaruh Technology Usage, E- Networking Dan Government...

\title{
Pengaruh Technology Usage, E- Networking Dan Government Support Terhadap Keberhasilan Entrepreneur Di Jakarta
}

\author{
Livia dan Kartika Nuringsih \\ Program Studi Manajemen Fakultas Ekonomi, Universitas Tarumanagara, Jakarta \\ Email: Most.girlz@gmail.com
}

\begin{abstract}
The purpose of this study is to examine the effect of technology usage, enetworking and government support to entrepreneur success in Jakarta. The sample as selected by a nonprobability sampling method of 100 respondens. The results of this study indicate that on technology usage, e-networking does not significantly influence the success of entrepreneurs in Jakarta and there is a significant on government support influence on the success of entrepreneurs in Jakarta.
\end{abstract}

Keywords: Technology Usage, E-Networking, Government Support, Entrepreneur Success.

\begin{abstract}
Abstrak: Tujuan dari penelitian ini adalah untuk menguji pengaruh technology usage, enetworking dan government support terhadap keberhasilan entrepreneur di Jakarta. Sampel dipilih menggunakan metode nonprobability sampling sebesar 100 responden. Hasil penelitian ini menunjukan bahwa pada technology usage dan e-networking tidak berpengaruh secara signifikan terhadap keberhasilan entrepreneur di Jakarta dan terdapat pengaruh yang signifikan pada government support terhadap keberhasilan entrepreneur di Jakarta.
\end{abstract}

Kata kunci: Technology Usage, E-Networking, Government Support, Keberhasilan Entrepreneur, Keberhasilan Wirausaha.

\section{LATAR BELAKANG}

Bisnis di era digital memberikan peluang bagi entrepreneur untuk membuka dan memperluas bisnis lebih efektif dan efisien. Teknologi informasi menciptakan koneksi antara bisnis dan organisasi memiliki potensi untuk menjangkau lebih banyak konsumen, memperkenalkan produk dan layanan baru dengan cepat dan berkolaborasi dengan 
pemasok dan mitra bisnis dari seluruh dunia serta dapat menyediakan informasi tentang konsumen dan pasar melalui internet.

Menurut Kotler \& Armstrong (2012) E-Commerce merupakan saluran online yang dapat dijangkau seseorang melalui komputer yang digunakan pebisnis melalui aktivitasnya dan konsumen untuk mendapatkan informasi dalam menentukan pilihan produk dan jasa yang ditawarkan. Tujuan wirausaha menggunakan E-Commerce untuk mendapatkan dan menjaga loyalitas konsumen serta memberikan kemudahan mendapatkan produk dan layanan yang diberikan secara fleksibel tanpa terbatas waktu dan tempat.

Disamping itu, Pemerintah melaksanakan program untuk mendukung kesuksesan wirausaha dalam menjalankan Online Businessnya. Dikutip dari Kominfo (2017), Kementrian perindustrian telah menyiapkan langkah- langkah dalam menghadapi era industry 4.0. Pemerintah memiliki visi untuk menempatkan Indonesia sebagai Negara dengan kapasitas digital ekonomi terbesar di Asia Tenggara pada tahun 2020 dengan menerbitkan paket kebijakan ekonomi XIV sebagai peta jalan E-Commerce.

E-Networking sebagai jaringan supplier penyedia produk, dan layanan yang terpadu untuk konsumen secara online. Wirausaha harus menjaga hubungan yang baik dengan para pemasok dan mitra bisnis agar bisnis dapat memberikan kualitas produk dan layanan yang baik dan konsisten.

Menurut Durrie dan Soldberg ( 2006), E- Networking sebagai hubungan yang saling terkait antara individu dan organisasi yang terdiri atas supplier, reseller dan tenaga pemasaran untuk mencapai pasar global dengan konsumen sebagai tujuan akhir untuk memberikan produk dan layanan yang baik.

Dukungan pemerintah dibutuhkan untuk kesuksesan wirausaha untuk menjalankan bisnis di negaranya. Pemerintah memberikan peraturan, hukum, sanksi, hak dan kewajiban yang harus ditaati wirausaha agar perusahaan terlindungi dan memiliki siklus hidup perusahaan dalam jangka panjang secara sah dimata negara dan hukum. Pemerintah Indonesia mendorong perkembangan ekonomi tradisional yang bergeser dan semakin luas ke bisnis digital melalui basis industri dan perdagangan elektronik (E-Commerce).

Tujuan penelitian ini adalah untuk mengetahui apakah technology usage, e-networking dan government support memiliki pengaruh terhadap keberhasilan entrepreneur di Jakarta. Hasil penelitian ini diharapkan dapat menambah referensi penelitian mengenai hal - hal 
yang memperngaruhi keberhasilan entrepreneur. Sedangkan untuk masyarakat khusunya yang memiliki jiwa wirausaha dapat mengetahui dan mengembangkan potensinya dalam menjalankan bisnis atau memulai suatu bisnis.

\section{KAJIAN TEORI}

Pengertian Entrepreneur/ wirausaha menurut Ebert dan Griffin (2015) adalah pelaku bisnis yang menerima risiko dan peluang terkait dengan penciptaan dan pengelolaan usaha baru. Penggunaan teknologi informasi sangat penting bagi wirausaha melalui $E$ Commerce sebagai MarketPlace untuk menjalakan bisnis secara online dan offline secara bersamaan. Selain E-Commerce, E-Business menunjukan aspek online business secara menyeluruh. Menurut Kotler (2012) E-Business berkaitan secara menyeluruh dengan proses bisnis termasuk value chain: pembelian secara elektronik (electronic purchasing), manajemen rantai suplai (supply chain management), pemrosesan order elektronik, penanganan dan pelayanan kepada pelanggan, dan kerja sama dengan mitra bisnis.

\section{Technology Usage}

Menurut Adeosun (2009) Penggunaan teknologi informasi memberikan nilai positif bagi strategi manajemen yang terkait dengan aspek komunikasi, akses informasi, pengambilan keputusan, manajemen data dan knowledge management pada sebuah perusahaan.

Menurut Ebert \& Griffin (2015) Penggunaan Teknologi Informasi adalah Beragam perangkat dan alat untuk menciptakan, menyimpan, mempertukarkan, dan menggunakan informasi dalam beragam moda, mencakup citra, visual, suara, multimedia dan data bisnis, telah mengubah struktur organisasi bisnis yang secara radikal mengubah cara karyawan dan konsumen bertinteraksi. Penggunaan Teknologi informasi dapat meningkatkan produktivitas, memperbaiki operasi dan proses bisnis, menciptakan peluang bisnis baru dan berkomunikasi serta bekerja dengan cara yang moderen.

Berdasarkan uraian diatas Technology Usage diartikan sebagai cara mengoperasikan dan mengubah bisnis lebih moderen, berbeda dan inovatif lewat tantangan dan peluang baru wirausaha untuk memberikan nilai tambah bagi konsumen, pelanggan dan mitra bisnis. 


\section{E-Networking}

Komunikasi yang efektif adalah kunci keberhasilan perusahaan, dimulai dengan terjaganya hubungan baik dengan mitra bisnis dalam hubungan pribadi dan professional melalui $E$ Networking. Menurut Diaz dan Rodriguez (2006) E-Networking sebagai relational capabilities yaitu cara membangun keunggulan bersaing dan sulit untuk ditiru dengan memiliki kemampuan membangun relationship, pencapaian kerjasama, saling bertukar pengetahuan dan informasi, serta menciptakan nilai bersama dan kordinasi antar organisasi.

Selanjutnya, Menurut Huggins (2010) E- Networking merupakan sumber daya dan modal yang dihasilkan melalui jaringan elektronik antar perusahaan. E- Networking dibedakan berdasarkan sumber daya menjadi network capital dan social capital, melihat dari beberapa dimensi yaitu source, mechanism, object dan impact.

Berdasarkan uraian diatas E-Networking merupakan jaringan yang dibangun dengan mitra bisnis untuk dapat mengakses sumberdaya dan pengetahuan secara professional melalui pemanfaatan hubungan berdasarkan prinsip sosial dan ekonomi.

\section{Government Support}

Dukungan pemerintah dengan merilis Paket Kebijakan Jilid XIV yang fokus pada perdagangan elektronik (E-Commerce) dan ekonomi digital. Ekosistem ekonomi digital saat ini terus berkembang dengan hadirnya E-Commerce memberi pilihan baru bagi para pengguna, wirausaha maupun konsumen dalam berinteraksi. E-commerce membuka peluang lapangan kerja, baik langsung maupun tak langsung.

\section{Keberhasilan Entrepreneur}

Menururt Mitrani (2006) entrepreneurship adalah sebuah usaha menciptakan cara, metode, produk, teknologi baru dalam usaha untuk memberikan pelayanan yang lebih baik untuk mendapatkan keuntungan yang lebih besar dan mencapai keberhasilan usaha.

Selain itu, Menurut Suryana (2009) keberhasilan wirausaha adalah tujuan utama membangun perusahaan dengan segala aktivitas pada perusahaannya untuk membawa keadaan lebih baik dan unggul dari masa sebelumnya. 
Berdasarkan definisi diatas, Kesimpulan dari keberhasilan entrepreneur adalah hasil yang didapatkan dalam proses menciptakan cara, metode, produk, teknologi baru dalam usaha untuk memberikan pelayanan yang lebih baik kepada konsumen dan membangun hubungan yang baik dengan mitra bisnis untuk mencapai tujuan usaha.

Berdasarkan uraian di atas, maka hipotesis penelitian sebagai berikut:

H1 : Technology Usage memiliki pengaruh yang positif terhadap keberhasilan Entrepreneur di Jakarta.

$\mathrm{H} 2$ : E-Networking memiliki pengaruh yang positif terhadap keberhasilan Entrepreneur di Jakarta.

H3 : Government Support memiliki pengaruh yang positif terhadap keberhasilan Entrepreneur di Jakarta.

\section{METODOLOGI}

Desain penelitian ini adalah conclusive research design dengan jenis penelitian konklusif kausal. Populasi dalam penelitian ini adalah wirausaha di Jakarta. Metode pengambilan pemilihan sampel yang digunakan dalam penelitian ini adalah judgmental / purposive sampling. Sampel dalam penelitian ini sebesar 100 sampel. Pada penelitian ini, pengujian data dilakukan dengan metode PLS-SEM dapat dilakukan dengan melihat nilai t-statistics pada path coefficient (Hair dkk., 2011). Pengukuran nilai t-statistics dapat dilakukan dengan menggunakan metode bootstrapping (Henseler dkk., 2009). Tabel 1 menunjukan pengukuran data dengan operasionalisasi variabel yang terdiri dari beberapa indikator dan sumber.

Tabel 1. Variabel pengukuran data

\begin{tabular}{|c|c|c|}
\hline Variabel & Jumlah Item & Sumber \\
\hline $\begin{array}{l}\text { Technology } \\
\text { Usage }\end{array}$ & 5 & Harlan (2014) \\
\hline E- Networking & 3 & Ginting \& Maria (2014) \\
\hline Government Support & 8 & Lukito (2017) \\
\hline Keberhasilan & 5 & Ocatavia (2015) \\
\hline
\end{tabular}


Livia dan Nuringsih: Pengaruh Technology Usage, E- Networking Dan Government...

Entrepreneur

\section{HASIL ANALISIS DATA}

Berdasarkan data yang telah dikumpulkan, diketahui bahwa mayoritas responden yang menjadi wirausaha di Jakarta adalah yang berusia 21- 30 tahun dengan wirausaha perempuan sebanyak 66 orang $(66 \%)$ dan wirausaha laki- laki sebanyak 34 orang (34\%) yang berdomisili usaha terbanyak berada di Jakarta pusat sebanyak 60 orang (60\%), lamanya usia usaha antara 3 sampai 5 tahun sebanyak 71 orang (71\%), jumlah karyawan wirausaha mendominasi kurang dari 5 orang sebanyak 63 orang (63\%) dan menggunakan sistem online sebanyak 86 orang (86\%). Pengukuran obyek penelitian diukur menggunakan skala likert lima poin dengan 1 menunjukan "sangat tidak setuju” dan 5 menunjukan "sangat setuju”. Gambar 1 menunjukan pengukuran masing- masing variabel dan sumbernya, intrumen tersebut telah dilakukan analisis validitas dengan hasil analisis loading factor diatas 0,7. Sementara untuk analisis reliabilitas didasarkan pada nilai cronbach's alpha yang masing - masing hasilnya menunjukan nilai lebih dari 0,6 sehingga semua faktor dalam penelitian adalah reliabel (Maholtra 2010). Pada penelitian ini, pengujian data dilakukan dengan metode PLS-SEM dapat dilakukan dengan melihat nilai t-statistics pada path coefficient (Hair dkk., 2011). Pengukuran nilai t-statistics dapat dilakukan dengan menggunakan metode bootstrapping (Henseler dkk., 2009). 


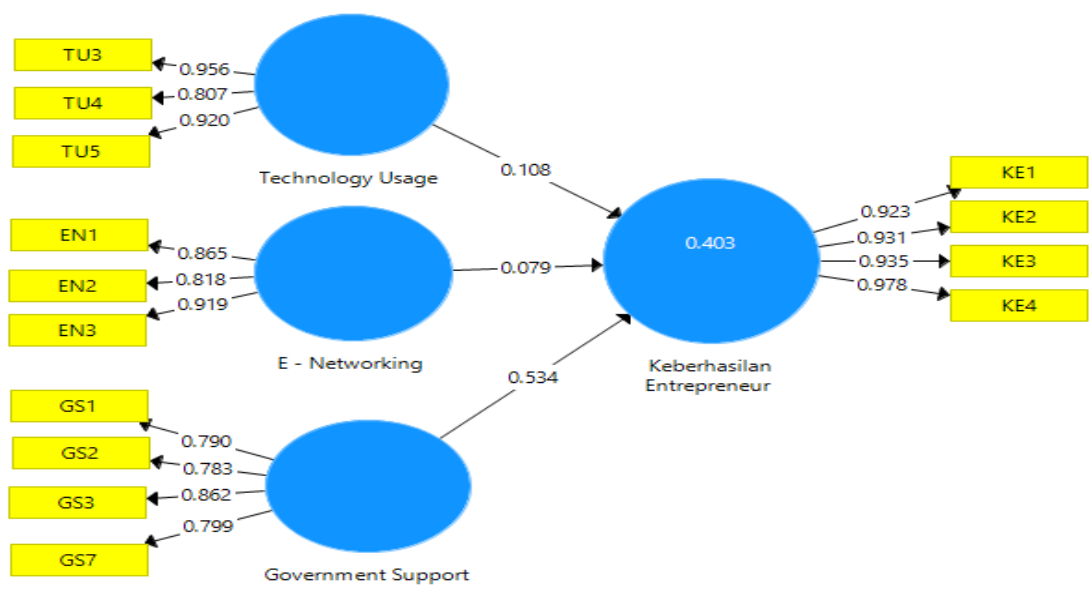

\section{Gambar 1. Hasil nilai Loading Factor}

hipotesis penelitian ini akan dinyatakan signifikan apabila variabel tersebut memiliki nilai t-statistics $>1,96$ dengan p-values $\leq 0,05$ Cohen (1988). Hasil analisis data secara singkat tertera pada tabel 2 sebagai berikut:

\section{Tabel 2. Hasil Pengujian Hipotesis}

\begin{tabular}{|c|c|c|c|}
\hline Variabel & $\begin{array}{c}\text { Original } \\
\text { Sampel }\end{array}$ & t- statistik & $\mathrm{p}$ - values \\
\hline $\mathrm{TU} \rightarrow \mathrm{KE}$ & 0,108 & 0,566 & 0,572 \\
\hline $\mathrm{EN} \rightarrow \mathrm{KE}$ & 0,079 & 0,589 & 0,556 \\
\hline $\mathrm{GS} \rightarrow \mathrm{KE}$ & 0,534 & 2,869 & 0,004 \\
\hline
\end{tabular}

\section{DISKUSI}

Berdasarkan hasil pengujian hipotesis, pada pengujian hipotesis pertama (H1) mengenai pengaruh technology usage terhadap keberhasilan entrepreneur pada tabel 2 memberikan hasil pengujian 0,572>0,05 sehingga $\mathrm{H} 1$ ditolak, yaitu tidak terdapat pengaruh yang signifikan technology usage terhadap keberhasilan entrepreneur. Hasil penelitian tersebut tidak sesuai dengan hasil penelitian Fathen \& Egide Karuranga (2013) Menyatakan bahwa tingkat adopsi teknologi yang berada didaerah metropolitan yang cenderung lebih cepat dan volume yang lebih tinggi dalam mengadopsi teknologi 
informasi (e-business). Penggunaan teknologi dapat memberikan pengaruh positif terhadap keberhasilan wirausaha dan keunggulan bersaing.

Berdasarkan hasil pengujian hipotesis kedua (H2) mengenai pengaruh e- networking terhadap keberhasilan entrepreneur pada tabel 2 memberikan hasil 0,556 $>0,05$ sehingga H2 ditolak, yaitu tidak terdapat pengaruh yang signifikan e- networking terhadap keberhasilan entrepreneur. Hasil penelitian tersebut bertolak belakang dengan hasil penelitian Babakus et.al (2006) menunjukkan bahwa untuk lebih meningkatkan keberhasilan usaha maka wirausaha harus lebih proaktif dalam menjalin hubungan dengan anggota mitra bisnis domestik maupun internasional.

Berdasarkan hasil pengujian hipotesis ketiga (H3) mengenai pengaruh Government Support terhadap keberhasilan entrepreneur pada tabel 2 memberikan hasil 0,004 $<0,05$ sehingga $\mathrm{H} 3$ tidak ditolak, yaitu terdapat pengaruh yang signifikan government support terhadap keberhasilan entrepreneur. Hasil penelitian ini sejalan dengan penelitian yang dilakukan Srun Lim Song et.al (2016) yang dilakukan di Cambodia yang menyatakan terdapat pengaruh yang positif terhadap keberhasilan wirausaha di negaranya dengan adanya dukungan pemerintah berupa konsultasi, pelatihan, modal dan perluasan pasar.

\section{PENUTUP}

Berdasarkan hasil analisis yang telah dilakukan dalam penelitian ini membuktikan bahwa technology usage dan e-networking tidak memiliki pengaruh yang signifikan terhadap keberhasilan entrepreneur di Jakarta. kemudian pada government support terdapat pengaruh yang signifikan terhadap keberhasilan entrepreneur di Jakarta. variabel government support memiliki pengaruh yang signifikan terhadap keberhasilan entrepreneur hal ini membuktikan bahwa pemerintah mempunyai peranan yang besar untuk memajukan wirausaha melalui peta jalan e-commerce yang direncanakan.

Bagi penelitian berikutnya, disarankan untuk menambah variabel lain yang dapat mempengaruhi keberhasilan wirausaha dan memperluas pilihan jangkauan pengambilan sampel serta menambah jumlah pengambilan sampel serta menggunakan metodologi yang berbeda untuk mengembangkan penelitian.

\section{DAFTAR PUSTAKA}

Adeosun, O. O., Adeosun, T. H., \& Adetunde, I. A. (2009). Strategic application of information and communication technology for effective service delivery in banking industry. Journal of Social Sciences, 5(1), 47-51.

Diaz, Manuel R.danT.F.E.Rodriguez (2006). Redesigning the Supply Chain: Reengineering, Outsourcing, and Relational Capabilities. Business Process Management Journal. 12(4), 483-502. 
Ebert, Griffin (2015) Pengantar Bisnis. Edisi 10. Jakarta : Erlangga.

Emin Babakus, Ugur Yavas, Antti Haahti, (2006) "Perceived uncertainty, networking and export performance: A study of Nordic SMEs", European Business Review, 18 (1), 4-13.

Jabeur, Fathen \& Egide Karuranga. (2013). Timeline of Initial Perceptions and Adoption of e-Business Among Quebec Forestry Sector SMEs. Communications of the IIMA. 13.3 (Aug. 2013): p1.

Hair, J. F., Ringle, C. M., \& Sarstedt, M. (2011). PLS-SEM: Indeed a Silver Bullet. The Journal of Marketing Theory and Practice, 19(2), 139-151.

Henseler, J., Ringle, C. M., \& Sinkovics, R. R. (2009). The use of partial least square path modeling in International Marketing. Advances in International Marketing, 20(1), 277-319.

Huggins, Robert. (2010). Network Resources and Knowledge Alliances : Sociological Perspectives on inter Firm Network as Innovation Facilitators.

Kominfo. (2017) Kemenperin kaji implementasi "Industry 4.0".

Kotler, Philip and Gary Armstrong. (2012). Prinsip - Prinsip Pemasaran. Edisi12. Jilid 1. Jakarta : Erlangga.

Malhotra, N.K. (2010). Marketing Research. England: Pearson Education Limited.

Mitrani. (2006). Manajemen sumber daya manusia berbasis kompetensi. Jakarta: Intermasa.

Terrence C, Sebora, Sang M lee dan Nittana Sukasame, (2008) Critical success factors for e-commerce entrepreneurship: an empirical study of thailand. 